\title{
Economia política da saúde no Brasil: quem são seus pesquisadores e o que pesquisam?
}

\author{
Daniel Figueiredo de Almeida ALVES ${ }^{(1)}$ \\ Leonardo CARNUT $^{(1)}$ \\ Áquilas Nogueira MENDES ${ }^{(1)}$ \\ ${ }^{(1)}$ Faculdade de Ciências Médicas da Santa Casa de São Paulo - FCMSCSP, São Paulo, SP, Brasil.
}

Recebido: 28 jan 2019 Aceito: 10 fev 2019

Autor de correspondência: d.fig94@gmail.com

Conflito de interesses: Os autores declaram não haver nenhum interesse profissional ou pessoal que possa gerar conflito de interesses em relação a este manuscrito.

\section{Resumo}

Com o decorrer do processo histórico de desenvolvimento das forças produtivas sob a égide do modo de produção capitalista, a questão da saúde cresce gradativamente em importância e assume papel destacado tanto na reprodução da força de trabalho, como no processo de acumulação. Porém, a saúde somente se fortaleceu como objeto direto de estudo das ciências econômicas com os avanços dos conflitos imanentes ao capitalismo. Desse modo, não é de espantar que a escola de pensamento neoclássica considere a saúde como tema de teorização e pesquisa de caráter nobre, já que essa sistematização é funcional a lógica de valorização do capital. Entretanto, este desenvolvimento das forças produtivas e, por consequência, aprofundamento das contradições - imanentes ao modo de produção capitalista - não favorece somente a elaboração dos paradigmas e sistematização do pensamento neoclássico, seus críticos também bebem dessa mesma fonte. Mais especificamente, a análise marxiana contida na crítica a economia política clássica e seus comentadores inauguram o entendimento que os níveis de saúde de uma população são determinados pelos seus condicionantes materiais e não somente pelo acesso a assistência à saúde. Esta crítica se contrapõe diretamente aos axiomas neoclássicos que insistem em permanecer no estreito entendimento da microeconomia - endereçando a problemática da saúde a resoluções de ordem meramente técnico-gerencial - se negando a enxergam a saúde na totalidade de suas relações sociais. A partir desta problemática, este artigo tem como objetivo mapear os pesquisadores que trabalham na área de economia política da saúde no Brasil para discutir sobre o papel da economia política na área da economia da saúde e sua contribuição para tencionar o pensamento econômico. Portanto, empregou-se uma análise de cunho quantitativo, de modalidade descritiva. Fez-se necessário identificar quais são os pesquisadores que se dedicam à área da economia da saúde. Para isso, foi realizada uma busca na plataforma Lattes - currículo eletrônico compulsório que todos os pesquisadores brasileiros devem ter preenchidos e atualizados junto ao Ministério da Ciência e Tecnologia - com descritor 'economia da saúde' e circunscrevendo apenas os doutores. Com o uso deste critério, dos 471 dos currículos identificados em uma primeira etapa de busca, apenas 254 (53,93\%) podem ser considerados economistas da saúde, o que se considerou como o 
total de pesquisadores (100\%) que se dedicam cotidianamente ao desenvolvimento da economia da saúde no Brasil. Uma vez que os pesquisadores, do campo em questão, foram delimitados realizou-se uma busca em seus currículos com o descritor economia política. Desta vez, sem nenhuma modalidade de filtro, considerando apenas a presença categórica do descritor, o que evidenciou que 29,92\% (76) dos pesquisadores apresentavam a presença do descritor economia política. Com o intuito de aprofundar a descrição dos economistas da saúde foi estudado a maneira com que se distribuíam em suas graduações - primeira e segunda - e área de doutorado. Na primeira graduação é evidente o predomínio de dois cursos: Ciências Econômicas 34,25\% (87) e Medicina 26,38\% (67), a maioria dos pesquisadores não apresentavam segunda graduação 94,88\% (241) e na área de doutorado mostrou-se a preponderância de três áreas - Saúde Coletiva/Saúde Pública/Medicina Preventiva 29,13\% (74), Economia 27,95\% (71) e Ciências Médicas 9,84\% (25). Após essa primeira aproximação - que delimitou os pesquisadores, a familiaridade com as análises da economia política, graduações e área de doutorado - realizou-se um mapeamento da produção de artigos publicados em periódicos científicos nas seguintes subáreas: Financiamento; Política de Saúde; Gestão em Saúde; e Análise/Avaliação de Custo, Efetividade e Eficiência. Foi identificado que 20,47\% (52) dos pesquisadores produzem na subárea do Financiamento; $13,39 \%$ (34) na subárea de Política de Saúde; 20,87\% (53) na subárea de Gestão em Saúde; e 42,52\% (108) na subárea de Análise/Avaliação de Custo, Efetividade e Eficiência. Além disso, estratificando-se a produção de Análise/Avaliação de Custo, Efetividade e Eficiência pela área de doutorado é possível notar uma predisposição por autores provenientes de áreas da saúde, principalmente, Saúde Coletiva/Saúde Pública/Medicina Preventiva 31,48\% (34); e Ciências Médicas 18,52\% (20), desse modo, ocupando maior relevância que pesquisadores provenientes da área de Economia. Esta predileção do pensamento neoclássico pela gestão e análise de custo deve-se pela restrição de somente trabalharem com categorias operacionalizáveis. Desse modo, direcionam suas análises somente para a indústria do cuidado à saúde, derivando desta a responsabilidade pelos níveis de saúde da população. Absolutamente tudo se reduz a expressão contábil, sendo a saúde correspondente à capacidade produtiva da sociedade em questão. A partir da impossibilidade da análise neoclássica em aproximar-se do objeto em questão - a saúde - por suas opções teórico-metodológicas dissocia a saúde da totalidade das relações sociais. Esta autoimposição de análises estritamente microeconômicas das quais a economia da saúde é herdeira corrobora para o reducionismo linear entre utilização dos serviços de saúde e níveis de saúde desta população. Isto pode ser constatado pela clara filiação da produção da economia da saúde às subáreas de Gestão em saúde e Análise/Avaliação de Custo, Efetividade e Eficiência. Além disso, no intuito de descrever os níveis de aproximação dos economistas da saúde com a Economia Política, além da primeira análise categórica, empregou-se uma análise de suas produções de artigos publicados em periódicos científicos com filiação a 
Economia Política e Economia Política da Saúde. Este aprofundamento da análise ressaltou que apenas $11,02 \%$ (28) dos pesquisadores filiam suas produções a Economia Política e, residualmente, 2,36\% (6) analisam à saúde por este prisma. Além disso, esses pesquisadores que filiam suas análises aos paradigmas abarcados pela economia política são, majoritariamente, advindos de doutorados na área da Economia 76,92\% (20); e com a área de Saúde Coletiva/Saúde Pública/Medicina Preventiva 11,54\% (3) assumindo um papel minoritário. O presente artigo procedeu uma primeira abordagem do campo da economia política da saúde. É possível dizer que os pesquisadores que se dedicam à economia política da saúde no Brasil são praticamente inexpressiva quando considerada a economia da saúde com um todo. A economia da saúde no Brasil é herdeira do pensamento neoclássico e sua produção científica em Economia Política, ainda mais especificamente no setor saúde, é vestigial.

Descritores: Economia da Saúde; Custos e Análise de Custo; Política de Saúde. 